\title{
ECONOMIC POLICY FOR THE ENVIRONMENT: THE ROLE OF INTERNATIONAL COOPERATION
}

\author{
M. Cristina Terra*
}

\section{Resumo}

Em uma abordagem normativa, estc artigo estuda a utilizaçāo de políticas econômicas quando externalidades negativas de produção/consumo sobre o mcioambiente atravessa as frontciras cntre países. Em um modelo com dois países, um dos países produz um bem que polui a atmosfera, e o outro um bem que destrói a sua floresta tropical. A poluiçāo destrỏi a camada de ozônio, cnquanto que a floresta tropical ajuda na sua reconstrução. Duas soluçōes são analisadas: a solução coopcrativa, onde os dois países implementam a solução de otimização global; c a solução nāo-coopcrativa, onde cacla país scparadamente implementa a melhor solução do ponto de vista nacional. O resultado principal deste artigo é que, scm coordcnação intcrnacional, a implementaçāo de políticas que visam a proteção do mcio ambientc podem levar a um decréscimo do bem-estar social. Este resultado é decorrente do fato dos países aproveitarem a oportunidade e, no pacote de medidas, introduzircm políticas protccionistas visando explorar o seu poder de monopólio no mercado mundial de bens.

\section{Abstract}

In a normative approach, this paper studics the use of economic policy when environmentally harmful extcrnalitics of production/consumption cross the countries' frontiers. In a model with two countries, one of the countries produces an air polluting good, while the other produces a good that destroys its rain forest. Pollution destroys the ozone laycr, and the rain forest helps in rebuilding it. Two solutions will be analyzed: the coopcrative solution, where the two countries implement the globally optimizing solution; and the non-cooperative solution, wherc sach country separatcly implements the national best allocation. The main result of this paper is that, absent worldwide coordination, the implementation of envirommental policies could actually worsen wclfare. The reason is that the countrics would take the opportunity to introduce protectionist policies to exploit their monopoly power in the world market for goods.

\footnotetext{
*Departamento de Economia - PUC/RJ

I am indebted to Genc Grossman and Giuscppe Bertola for useful comments and suggestions.

Financial support from CNPq (Conselho Nacional de Desenvolvimento Científico c Tecnológico) is gratefully acknowledged.
} 


\section{Introduction.}

There is a widespread concern about the environment. The "good health" of the planet, which has always been taken for granted, is now endangered. One of the difficulties of keeping a healthier enviromment is that most of the harm on the enviromment is the result of activities that are not harmful in the individual level, but are harmful if undertaken at a large scale, i.e., there is an externality problem. The ozone layer destruction is an example of such an externality, but is has a special feature: it affects all countries, and not only the one that causes the destruction. Economic policies that try to deal with this externality, which is one of the main concerns of the environmentalists ${ }^{1}$, will be studied.

The ozone layer protects the living beings of the planet from the ultra-violet rays. The amount of ozone in the atmosphere, therefore, enters positively in the utility function of the consumers. In the past, when ozone was not a scarce good, some more or less ozone would not affect anyone's well being, presumably, because there was more than enough to ensure a satisfactory protection for the planet's life. The situation has changed considerably. In some parts of the planet the ozone layer has decreased so much that it threatens the health of the people who live in those places. In this case, an increase in the amount of ozone in the atmosphere does increase the utility of the individuals.

In the model studied two countries are interacting. One of the countries, "North", produces a good that pollutes the air with substances that destroys the ozone layer. The other country, "South", possesses a rain forest that helps rebuilding the ozone layer. It, however, produces a good that causes the destruction of the forest in its production process. The question that will be addressed is: how should economic policy be used in a situation where there is this envirommentally harmful externality of consumption/production crossing the countries' frontiers?

This paper shows that the non-cooperative solution may lead to an allocation worse than the one in laissez-faire. The highest welfare

ISce, for cxample, The Economisl, 05/03/92. 
is achieved when the two countries act cooperatively in the implementation of their common welfare maximizing economic policy. If the two countries do not cooperate and each one pursues its own best allocation, not only they will not take into account the effect of their actions on the utility of the other country's consumers (which would make them value more envirommental improving policies), but they would also use the economic policy to exploit their monopoly power in the international goods market. Hence, the allocation resulting from the non-cooperative policy could be worse than the free market allocation.

The paper is organized as follows. Section 2 presents the model with the free market allocation. The cooperative solution is described in section 3, and the non-cooperative one in section 4 . Section 5 presents the conclusion.

\section{Free Market.}

The Model.

There are two countries, North and South, producing three goods, manufactures $(M)$, wood $(W)$ and baskets $(B)$. North has an endowment of capital $\left(K^{*}\right)$ and labor $\left(L^{*}\right)$ that allows it to produce manufactures through the production function $f(K, L)$, which has constant returns to scale in both factors, but diminishing returns to labor when capital is held fixed. The country also produces baskets which uses only labor in its production function with constant returns to scale.

South has an endowment of rain forest $\bar{T}$ which can be used to produce wood. The production of wood requires one unit of forest (i.e., one tree) for each unit of wood produced, and no other factors of production. The rain forest reconstitutes itself at a rate that depends positively on its size, and it diminishes by the amount of trees that are cut. Hence:

$$
T_{t}=G\left(T_{t}\right)-W_{r}
$$

where $T_{t}$ is the size of the rain forest, and $W_{t}$ the production of wood in period $\tau$. 
The function $G\left(T_{t}\right)$ represents the natural reproduction of the rain forest. It is a concave function, as illustrated in figure 1.

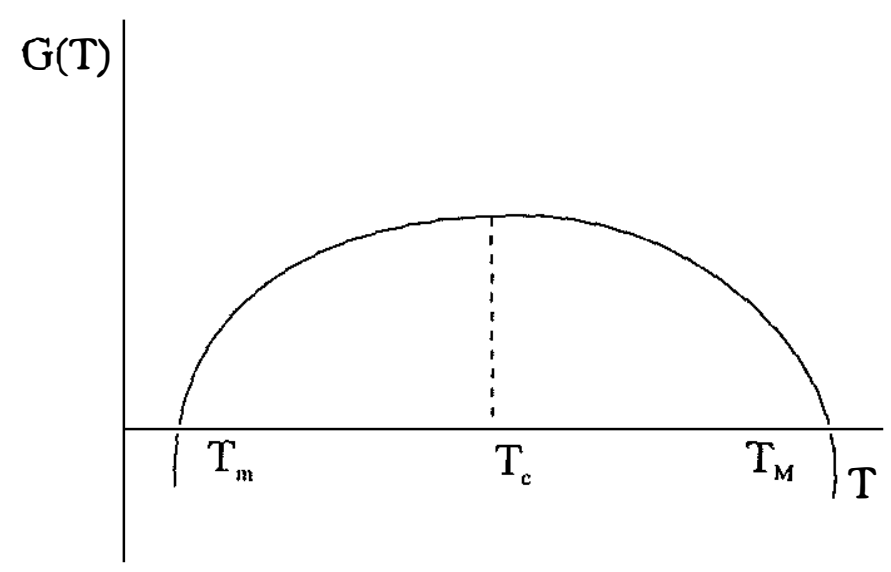

Figure 1.

The intuitive reasoning for this adjustment behavior is as follows. The soil of a rain forest is not very rich, so that if the forest is cut, the soil loses its fertility quickly. When the forest is too small, below $T_{m}$, the few sparse trees are not sufficient to nourish and seed the soil, then the size of the soil decreases. Forests in the interval $\left[T_{m}, T_{c}\right)$ reproduce themselves at an increasing rate, i.e., $G\left(T_{t}\right)>0$. But the rate of increase is decreasing, because the area available for the forest to grow is constant, and so is the water supply. When the forest gets larger than $T_{c}$, the constancy of the elements begins to compromise its capacity to reproduce itself. For the interval $\left(T_{c}, T_{M}\right)$ the forest increases at a decreasing rate, and if the forest is larger than $T_{M}$ it will actually decrease.

The interesting feature of the goods that will be explored in this paper are the externalities from their production/consumption. Good $B^{\prime} s$ production or consumption yields no externality, while good $M^{\prime} s$ 
consumption causes air pollution and good $W^{\prime} s$ production destroys the rain forest. The air pollution is responsible for the destruction of the ozone that protects the planet's life from ultra-violet rays. The rain forest, on the other hand, helps in the ozone reconstruction. If too much of goods $M$ and $W$ are produced, a lot of the ozone will be destroyed without proper replacement. The amount of ozone is represented by the function;

$$
z_{\tau}=h\left(T_{\tau}, P_{\tau}\right)
$$

where $z_{\tau}$ is the amount of ozone and $P_{\tau}$ the amount of pollution in period $\tau$. Air pollution depends positively on the total consumption of manufactures from the $\mathrm{m}$ consumers in the world:

$$
P_{\tau}=p\left(C_{M \tau}^{m}\right)
$$

where $C_{M \tau}^{m 2}=\sum_{i=1}^{m} c_{M \tau}^{i}$, and $c_{M \tau}^{i}$ is the consumption of manufactures from individual i.

Consumers derive their utility from the consumption of manufactures, wood and baskets, and from the amount of ozone in the atmosphere. They have identical, Cobb-Douglas preferences with respect to $M, W$ and $B$. Hence, the utility of a representative consumer is represented by:

$$
U_{t}=\int_{t}^{\infty} e^{\rho(\tau-t)}\left\{\alpha_{B} \log C_{B \tau}^{i}+\alpha_{M} \log C_{M \tau}^{2}+\alpha_{W} \log C_{W \tau}^{2}+\Theta\left(z_{\tau}\right)\right] d \tau .
$$

where $\Theta(\bullet)$ is an increasing function, $\rho$ is the (constant) intertemporal rate of substitution, and $c_{j \tau}^{i}$ is the amount of good $j$ consumed by the representative consumer.

The main assumption in this paper is that the economic agents do not take into account the effect of the consumption/production on the ozone layer. This means that the agent's perception is that:

$$
\frac{\partial U_{t}}{\partial c_{j \tau}^{i}}=\frac{\alpha_{j} e^{\int_{t}^{\tau} \rho_{s} d s}}{c_{j \tau}^{i}} \text { and } \frac{\partial U_{t}}{\partial j_{\tau}}=0 \quad \text { for } j=M, W, B \text {, and } \tau \geq t \text {. }
$$




\section{Free Market Allocation.}

In the market solution, firms will maximize their profits subject to the technology constraint, consumers will maximize their utilities subject to their budget constraint, and goods and labor markets will clear. Note that when maximizing their objective functions, neither consumers nor producers take into account the effect of their decision on the ozone layer. First, the equilibrium in North will be characterized.

North.

Producers in North have to decide how much to produce of manufactures and baskets. They have an endowment of capital to be used in the production of manufactures, and of labor to be used in the production of both goods. In perfect competition, they take prices as given, and hire factors up to the point where the value of marginal product of the factor equals its cost. In equilibrium, prices will adjust so that there is full employment of the factors of production. The profit maximizing condition in the baskets industry is given by:

$$
a p_{B}=w
$$

where $w$ is the wage rate and $a$ is the constant marginal productivity of labor in the industry. This equation determines the equilibrium wage rate of the economy.

The rental rate of capital adjusts so that the manufactures industry fully employs its endowment of capital (figure 2.c). Labor is hired in the industry up to the point where the value of marginal product of labor equals its cost, given the wage rate and the price of manufactures (figure 2.a). Finally, the amount of capital and labor in the production determines the amount of manufactures produced (figure 2.b).

The labor market clearing condition will determine how much of good $\mathrm{B}$ will be produced. It is represented in Figure 3.

On the demand side of the economy, consumers maximize their utilities (equation (4)) subject to a budget constraint represented in 
M. Cristina Terra

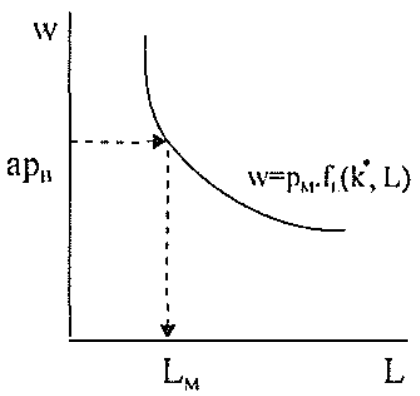

a

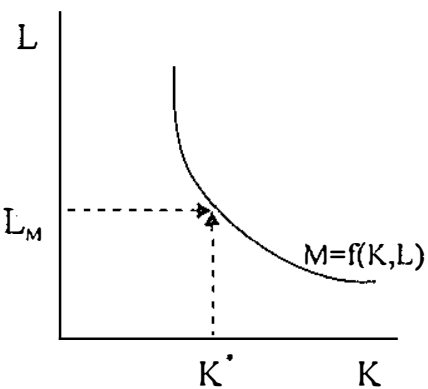

b

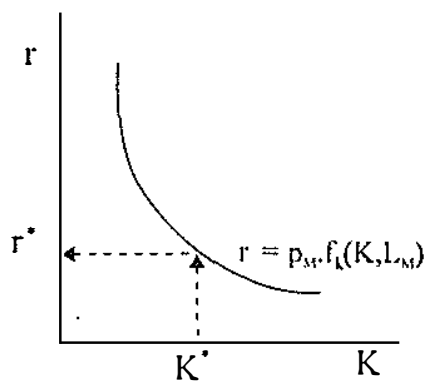

Figure 2. 


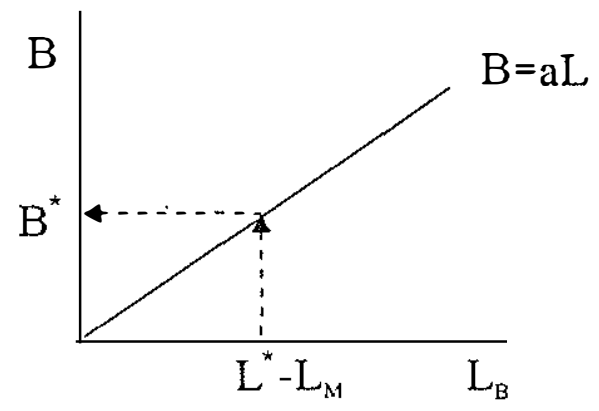

Figure 3.

the following equation ${ }^{2}$.

$$
\begin{aligned}
\int_{t}^{\infty} e^{-[R(\tau)-R(t)]}\left(p_{B \tau} c_{B \tau}^{i}+\dot{p_{M \tau}} c_{M r}^{i}+c_{W \tau}^{i}\right) d \tau \\
\leq \int_{t}^{\infty} e^{-[R(\tau)-\Gamma(t)]}\left(\frac{w_{\tau} L^{*}+r_{r} K^{*}}{m^{n}}\right) d r
\end{aligned}
$$

where $w_{\tau}=a p_{B \tau}, r_{\tau}=p_{M \tau} f_{k}\left(K^{*}, L_{M \tau}\right), R(\tau)=\int_{t}^{\tau} i_{s} d s, i$ is the interest rate, and $m^{n}$ is the amount of individuals living in Norih. To simplify the analysis, it is assumed that each individual receives as income an equal share of the country's total income.

This yields the following consumption pattern:

$$
p_{j \tau} c_{j \tau}=\frac{\alpha_{j}}{\alpha_{B}+\alpha_{M}+\alpha_{W}} E_{\tau} \quad \text { for } j=B, M, W
$$

where expenditure $E_{\tau}=\frac{w_{\tau} L^{*}+r_{\tau} K^{*}}{m n^{n}}$ in equilibrium. ${ }^{3}$

"Good "wood" is chosen to be the numerairc, and its price is set to equal 1.

${ }^{3}$ Although consumers may borrow or lend, they do not do so in cquilibrium from the solution of their dynamic optimization problem. 
Furthermore, the demand conditions yield:

$$
\frac{E_{\tau}}{E_{\tau}}=i_{\tau}-\rho
$$

After characterizing the equilibrium conditions in South, the general equilibrium of the economy will be determined.

South.

Consumers in South are the owners of the forest, so that their income is the revenue from the wood production. They maximize their utility (equation (4)) subject to the following budget constraint:

$$
\begin{aligned}
\int_{t}^{\infty} e^{-[R(\tau)-R(t)]}\left(p_{B \tau} c_{B \tau}+P_{M \tau} c_{M \tau}+c_{W \tau}\right) d \tau \\
\leq \int_{t}^{\infty} e^{-[R(\tau)-R(t)]}\left(W_{\tau}\right) d \tau
\end{aligned}
$$

where $m^{s}$ is the amount of individuals living in South, and, here again, the income of each individual is an equal share of the country's total income.

The conditions for solving the intertemporal maximization problem are the same as in North, i.e., equations (8), and (9) also hold for South.

The Wood industry uses as factor of production an exhaustible resource it owns: the rain forest. Hence, at any point in time, the amount of wood produced will affect the production possibilities in the future. The production decision in the Wood industry is, therefore, the result of an inter-temporal maximization problem. It maximizes the present value of its profits, subject to the forest's adjustment path constraint, and the fact that the amount of trees cut cannot exceed the size of the forest (the initial size of the forest is $\bar{T}$ ).

$$
\max \int_{t}^{\infty}\left[e^{i_{r}(\tau-t)} W_{\tau}\right] d \tau
$$




$$
\begin{aligned}
& \text { s.t. } \quad \dot{T}_{\tau}=G\left(T_{\tau}\right)-W_{\tau} \\
& W_{\tau} \leq T_{\tau} \\
& T_{t}=\bar{T}
\end{aligned}
$$

Assuming that the second constraint is not binding, i.e., that the optimal schedule for cutting trees will not be the destruction of the entire forest (which will be checked later), the first order conditions for the maximization of the problem are:

$$
\begin{aligned}
& \text { (i) } 1-\mu_{\tau}=0 \\
& \text { (ii) } \dot{\mu}_{\tau}-\mu_{\tau}\left[i_{\tau}-G^{\prime}\left(T_{\tau}\right)\right]=0 \\
& \text { (iii) } \quad \lim _{\tau \rightarrow \infty} e^{-i_{\tau}(\tau-i)} \mu_{\tau} T_{\tau}=0 \\
& \text { (iv) } W_{\tau}-T_{\tau} \leq 0
\end{aligned}
$$

where $e^{-i_{\tau}(\tau-t)} \mu_{\tau}$ is the costate variable associated with $T_{\tau}$. Its value is the marginal value of the forest at time $\tau$ from the point of view of time $t$.

Equation (12.iii) represents the tranversality condition. When time goes to infinity, either the "present marginal value" of the forest (i.e. the costate variable) goes to zero, or the size of the forest goes to zero.

Equations (13.i) and (13.ii) imply that $i_{\tau}=G^{\prime}\left(T_{\tau}\right)$. Using equation (9), the rate of growth of wood production is given by: ${ }^{4}$

$$
\frac{\dot{W}_{r}}{W_{\tau}}=G^{\prime}\left(T_{\tau}\right)-\rho
$$

Figure 4 illustrates the dynamics of the problem. All points in the positive orthand and below the $W=T$ schedule are feasible. The

${ }^{4}$ Remember that, in cquilibrium, $p_{B \tau} c_{B \tau}+p_{M \tau} c_{M \tau}+c_{W \tau}=W_{\tau}$. 


\section{Cristina Terra}

locus $\dot{W}=0$ is a vertical line on $T_{s}$, which is the size of the forest that makes $G^{\prime}\left(T_{s}\right)=\rho$. The intuition behind the relation between $\rho$ and $T_{s}$ is the following: the less patient the consumers are (i.e., the higher $\rho$ ), the lower will be the present value of consumption far in the future. Demand conditions will make the firm prefer to cut more trees today, instead of having a larger forest for the future. Hence, the less patient the economic agents are, the lower will be the optimal size of the forest. The locus $\dot{T}=0$ was described in figure 3 .

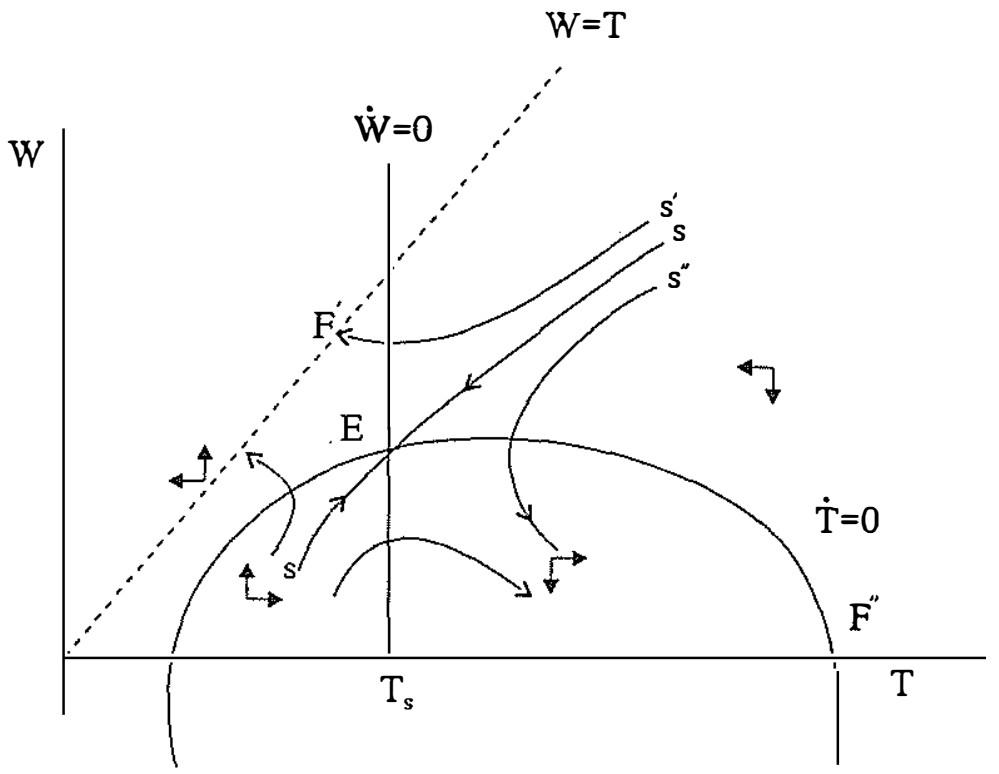

Figure 4.

The dynamics is as follows. On points above $\dot{T}=0$, the size of the forest is decreasing. The amount of trees that are being cut is higher than the reproduction rate of the forest, hence the forest shrinks. Below $\dot{T}=0$ the forest reproduces itself faster than the trees are taken away, and the forest gets larger. As for the variation 
of wood production, to the right of the $\dot{W}=0$ schedule the amount of trees cut over time decreases, and to the left it increases.

There exists one saddle path in the solution to the problem, i.e., one trajectory $\left(T_{\tau}, W_{\tau}\right)$ that satisfies the adjustment equations (1) and (13), the feasibility constraint (12.iv), and the transversality condition (12.iii). Appendix A shows why the only saddle path is the ss trajectory that leads to point $\mathrm{E}$ in figure $4 .^{5}$

The final step to characterize the market equilibrium is to make sure that the goods' market clear:

$$
C_{j}^{n}+C_{j}^{s}=j \quad \text { for } j=B, M, W,
$$

where $C_{j}^{n}$ and $C_{j}^{s}$ represent the total consumption of good $j$ by consumers at North and South, respectively.

With the three equations for consumption in North and in South represented in equation (8), and any two of the market clearing equations in equation (14), then $C_{j}^{\prime \prime}, C_{j}^{s}$ and $p_{j}$ ( for $j=B, M, W$ ) can be derived in terms of $B, M$, and $W$. W at each point in time is a point at the saddle path $s s$ in figure 4 . Finally, the profit maximizing conditions for the production of $B$ and $M$, represented in figures 2 and 3 , combined with the price equations determine the equilibrium prices and the equilibrium production level of $B$ and $M$. Those, in turn, are substituted back into the consumption equations to determine the equilibrium consumption levels of each good in each country.

The market equilibrium, however, is not efficient. When taking their decisions, the producers of wood did not take into account the effect of their activity on the ozone layer, nor the consumers took into account the effect of their consumption of manufactures on air pollution.

Next section derives the global plamner's solution to the problem, which indicates the efficient allocation for the world economy. The countries may implement the global plamner's allocation if they act cooperatively on an intervention scheme. In section 4, the allocation resulting from the solution of national planners is derived, and com-

${ }^{5}$ Obscrve that in the optimal path for cutting trecs the sccond constraints is actually not bicling, as was assumed above. 
pared to the global planner's one. The national planners' solution is the result of a policy intervention designed non-cooperatively.

\section{The Cooperative Solution.}

The cooperative solution is the resulting allocation when the two countries implement policies to maximize worldwide welfare. To derive the cooperative solution to the problem, it is necessary to derive the optimal allocation resulting from the maximization of welfare of a global planner, i.e., a plamner that takes into account the utility of consumers in both countries.

The global planner maximizes the present value of its welfare function, which has as arguments the utility of each consumer, subject to the rain forest adjustment rule, the production functions, and the factor endowments constraints. The problem is represented as: ${ }^{6}$

$\max \int_{t,}^{\infty} e^{-\rho(\tau-t)} \Omega\left[U\left(c_{M \tau}^{1}, c_{W \tau}^{1}, c_{B \tau}^{1}, z_{\tau}\right), \ldots, U\left(c_{M \tau}^{n \imath}, c_{W \tau}^{m}, c_{B \tau}^{m}, z_{\tau}\right)\right] d \tau$

s.t.

$$
\begin{gathered}
M \leq f\left(K^{*}, L_{M}\right) ; \\
W \leq T ; \\
B \leq a L_{B} ; \\
C_{M}^{n}+C_{M}^{s}=M ; \\
C_{W}^{n}+C_{W}^{s}=W ; \\
C_{B}^{n}+C_{B}^{s}=B ; \\
L_{M}+L_{B}=L^{*} ; \\
z=h\left(T, f\left(C_{M}^{n}+C_{M}^{s}\right)\right) ; \\
T=G(T)-W ;
\end{gathered}
$$

\footnotetext{
${ }^{6}$ The time subscripts are omitted wherever it is not confusing to do so.
} 


$$
T_{t}=\bar{T}
$$

where $\Omega[\cdot]$ is the welfare function $C_{i}^{n}=\sum_{i=1}^{m^{n}} c_{j}^{i}$ and $C_{i}^{s}=\sum_{i=1}^{m^{s}} c_{j}^{i}$ represent the consumption of the $m^{n}$ Northerners and the $m^{s}$ Southern consumers, respectively.

Solving the dynamic optimization problem, the following adjustment pattern in derived for the consumption of wood for the representative consumer: ${ }^{7}$

$$
\frac{\dot{c}_{W}^{i}}{c_{W}^{i}}=G^{\prime}(T)-\rho+c_{W}^{i} \frac{\sum_{k-1}^{m} \Omega_{k} U_{z}^{k} h_{t}}{\Omega_{i}}
$$

where $\Omega_{k}=\frac{\partial S_{2}}{\partial U\left(C^{k}, z\right)}, U_{z}^{k}=\frac{\partial U\left(c_{i s}^{k}, c_{1,}^{k}, c_{D}^{k}, z\right)}{\partial z}$, and $h_{T}=\frac{\partial h(T, P)}{\partial T}$.

Equation (16) yields:

$$
\frac{\dot{W}}{W}=G^{\prime}(T)-\rho+W \frac{\sum_{k=1}^{m} \Omega_{k} U_{z}^{k} h_{T}}{\Omega_{i}} .
$$

Figure 5 illustrates the dynamics of the problem. ${ }^{8}$

It is straightforward to check that the dynamics of the global plamner's solution for the production of wood is very similar to the market solution. The only difference between the two is the optimal adjustment patlı for the production of wood. Here the locus in which $\dot{W}=0$ is an upward sloping curve starting at point $\left(0, T_{s}\right)$, whereas in the market solution it was a vertical line at $T=T_{s}$. Using the same arguments as in the market solution, here there is only one saddle path, $s_{c} s_{c}$, leading to point $E_{c}$.

Comparing the trajectories of $W$ from the two problems, it is clear that the global planner solution indicates a lower production of wood at each point in time (supposing the size of the rain forest is initially the same in both problems). It also reaches the steady state at a larger forest size, and possibly at higher production level of wood. When the effect of the size of the forest on the ozone layer is

${ }^{7}$ The derivation of the cquation is in appendix $\mathrm{B}$.

${ }^{8}$ Note that $T_{s}$ in figure 5 represents the same valuc as $T_{s}$ in figure 4 . 


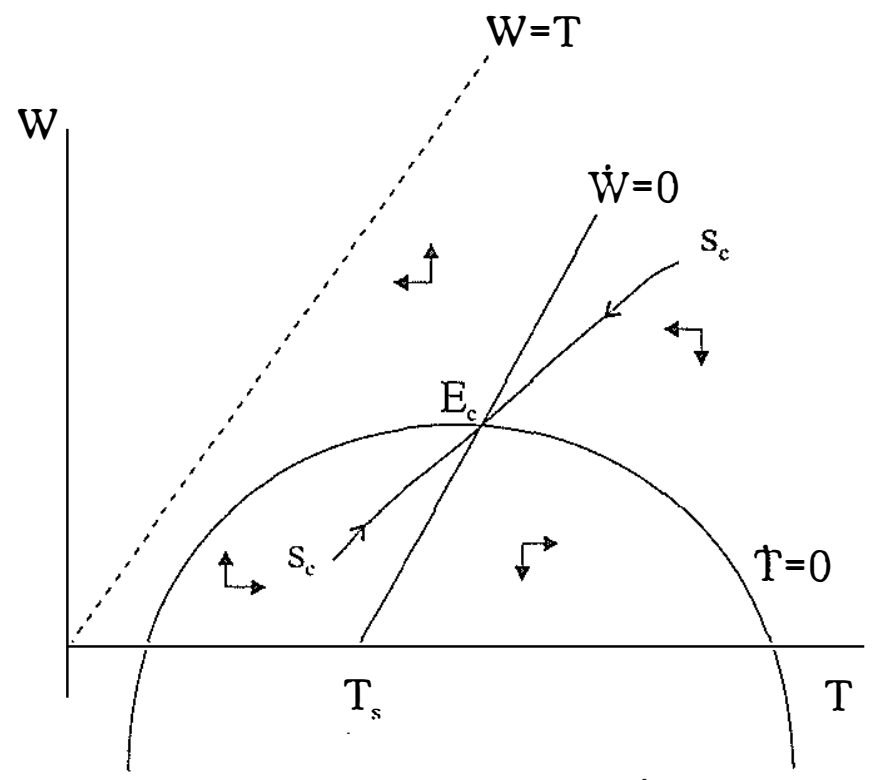

Figure 5.

taken into the account, it is preferable to give up some consumption of wood at each point along the optimal path in order to have, in the future, a larger forest, and therefore more ozone.

The global planner solution also differs from the market one regarding the production/consumption of manufactures decision. The first order condition from the global planner's maximization with respect to $c_{M}^{i}$ is:

$$
\sum_{k=1}^{M} \Omega_{k} U_{z}^{k} h_{M}+\pi_{m}-\phi_{m}=0
$$

where $\pi_{M}$ and $\phi_{M}$ are Lagrange multipliers associated to the market clearing and production function of manufactures constraints, respectively.

$\pi_{M}$ and $\phi_{M}$ in the optimal solution are interpreted as the shadow value of an extra unit of manufacture for the consumers, and an extra 
unit of manufacture for the producers, respectively. In a market equilibrium, these values stand for the consumer and the producer price of manufactures. In the market solution derived in section 2 those two values were equal, whereas here the consumer price of manufactures is higher than the producer price. This difference implies a different optimal decision of production and consumption.

To implement the central planner's allocation the governments have to make transfers to each consumer so that $\Omega_{i}=1 / \alpha_{i}$, where $\alpha_{i}$ is the Lagrange multiplier associated to the consumer's budget constraint in the market solution, and impose two taxes: The Northern government has to impose a production tax on manufactures equal to $\sum_{k=1}^{m} \Omega_{k} U_{z}^{k} h_{M}$, and the Southern govermment has to make a transfer to each forest owner equal to $\frac{\sum_{k=1}^{m} \Omega_{k} U_{\Sigma}^{k} h_{T}}{m \Omega_{i}}$ per unit of tree owned ${ }^{9}$. The production tax makes the producers of manufactures incorporate the effect of their production on the consumers' utility, and the transfer to forest owners makes the wood industry incorporate the effect of the size of the rain forest on the consumers' utility. Assuming that the function $h($.$) is linear in M$ and $T$, so that the taxes do not depend on the size of $C_{M}$ and $T$, the tax on manufactures will be constant over time while the transfer to forest owner will change proportionally to changes in $W$.

The solution presented above represents a cooperative solution, where both countries act in coordination to achieve a worldwide efficient allocation. However, it may be the case that political or institutional barriers prevent the two countries from cooperating. In that case, each country separately should seek the best way to improve its welfare. It may also be the case that one country gains from deviating singly from -the cooperative solution, then it would not be sustainable without some mechanism to offset the incentive to deviate. Each country's national planner optimal allocation will now be investigated.

\footnotetext{
${ }^{9}$ Each producer of wood takes the transfer as an exogenous value. Each producer is relatively small so that she does not take into account the effect of her own production on the value of the tax.
} 


\section{The Non-Cooperative Solution.}

The non-cooperative solution is the solution when the countries individually implement policies to maximize only their own welfare. The solution of the maximization of national planners' welfare indicates the allocation achieved without cooperation between the countries. North and Soutl will be studied in turn.

North.

The Northern planner wants to maximize the present value of a welfare function of the utilities of Southern consumers, subject to the factor endowiments, goods endowments, production functions, and the external balance constraints. Note that the Northern plamner takes into account the effect of their consumption and their export of manufactures on the ozone layer. ${ }^{10}$ The maximization problem faced by the Northern planner is represented by:

$\max \int_{t}^{\infty} e^{-\rho(\tau-t)} \Omega\left[U\left(c_{M \tau}^{1}, c_{W \tau}^{1}, c_{B \tau}^{1}, z_{\tau}\right), \ldots, U\left(c_{M \tau}^{m^{n}}, c_{W \tau}^{m^{n}}, c_{B \tau}^{m^{n}}, z_{\tau}\right)\right] d \tau$

s.t.

$$
\begin{gathered}
M \leq f\left(K^{*}, L_{M}\right) \\
B \leq a L_{B} ; \\
C_{M}^{n}=M+m_{M} ; \\
C_{W}^{n}=m_{W} ; \\
C_{B}^{n}=B+m_{B} ;
\end{gathered}
$$

\footnotetext{
${ }^{10}$ The Northern planner problem as presented below docs not incorporate the effect of the Northerners consumption of wood on its production, and, conscquently, on the size of the rain forest. If she did, she would possibly impose restrictions on their imports or consumption of wood, in order to induce a lower production of wood by South. This simplification docs imply that the solution to this problem is not the sccond best, but it makes the problem analytically tractable.
} 


$$
\begin{gathered}
z=h\left(T, f\left(C_{M}^{n}-m_{M}\right)\right) ; \\
L_{M}+L_{B}=L^{*} \\
P_{M}\left(m_{M}, m_{W}, m_{B}\right) m_{M}+P_{W}\left(m_{M}, m_{W}, m_{B}\right) m_{W} \\
+P_{B}\left(m_{M}, m_{W}, m_{B}\right) m_{B}
\end{gathered}
$$

where $m_{j}$ represents the net imports of good $j$, and $p_{j}\left(m_{M}, m_{W}, m_{B}\right)$ is the inverse of the supply function for good $j$.

The first order conditions for the maximization above imply a different allocation compared to the market equilibrium conditions. The difference comes from two sources: the first one is that the local planner takes into account the negative effect of the world consumption of manufactures on the utility of Northern consumers through its effect on the ozone layer, and the second one is that the local plamner perceives the possible exploitation of the country's monopoly power in the intermational goods' market.

To implement the allocation derived from the maximization above, the Northern government makes transfers to the consumers so that $\Omega_{i}=1 / \alpha_{i}$, and prices are normalized so that the multiplier of the balance of payments constraint equals zero. To deal with the distortions the plamner can use a combination of three different policies: trade policies, which include export taxes or subsidies and import tariffs or subsidies; consumption taxes or subsidies; and production taxes or subsidies. In this case the local plamner will introduce a production tax on manufactures equal to $\sum_{k=1}^{m^{n}} \Omega_{k} U_{z}^{k} h_{m}{ }^{11}$; an export tax on manufactures equal to $\sum_{k=M, W, B}\left[m_{k} \frac{\partial m_{k}\left(m_{M}, m_{W}\right.}{\partial m_{M}}\right.$; ano 1e): export tax on baskets ${ }^{12}$ equal to $\sum_{k=M, W, B}\left[m_{k} \frac{\partial_{p_{k}}\left(m_{M,}, m_{1,}, m_{B}\right)}{\partial m_{B}}\right]$; and an import subsidy on wood equal to $\sum_{k=M, W, B}\left[m_{k} \frac{\partial p_{k}\left(m_{M}, m_{W}, m_{B}\right)}{\partial m_{M}}\right]$ in absolute value. It is important to observe that the three latter policies are due to the exploitation of the monopoly power of the country

${ }^{11}$ Notc that a production tax is cquivalcnt to a combination of an export tax and a consumption tax of the same amount.

${ }^{12}$ If the country is a importer of baskcts, it should impose an import subsidy of the same absolute value. 
in the international goods market, and does not relate to the main externality problem we are concerned about here. The tax on manufactures production is constant over time, but the other taxes may vary during the adjustment period for the wood industry. The change in the production of wood affects the world supply function for the three goods.

After deriving the Southern plamner solution and its implementation scheme, the local plamners' allocation will be compared to the central planner's one.

South.

The Southern plamner maximizes the present value of a welfare function of the utilities of Southern consumers, subject to the production function, the good's endowments, the external balance constraints, the forest adjustment path, and the initial rain forest endowment:

$\max \int_{t}^{\infty} e^{-\rho(r-t)} \Omega\left[U\left(c_{M \tau}^{1}, c_{W \tau}^{1}, c_{B \tau}^{1}, z_{\tau}\right), \ldots, U\left(c_{M \tau}^{m^{s}}, c_{W \tau}^{m^{s}}, c_{B \tau}^{m^{s}}, z_{\tau}\right)\right] d \tau$

s.t.

$$
\begin{gathered}
W \leq T \\
C_{M}^{n}=-m_{M} ; \\
C_{W}^{n}=W-m_{W} ; \\
C_{B}^{n}=-m_{B} ; \\
z=h\left(T, f\left(C_{M}^{n}+C_{M}^{s}\right)\right) ;
\end{gathered}
$$

$$
\begin{gathered}
p_{M}\left(m_{M}, m_{W}, m_{B}\right) m_{M}+ \\
p_{W}\left(m_{M}, m_{W}, m_{B}\right) m_{W}+p_{B}\left(m_{M}, m_{W}, m_{B}\right) m_{B}=0 ; \\
\dot{T}=G(T)-W
\end{gathered}
$$


Economic Policy for the Enviromment

$$
T_{t}=\bar{T}
$$

Solving the dynamic optimization problem, the following adjustment path for the consumption of wood for a representative Southern consumer is derived: ${ }^{13}$

$$
\frac{c^{i s}}{c_{W}^{i s}}-\quad-\rho+c_{W}^{i s} \frac{\sum_{k=1}^{m s} \Omega_{k} U_{z}^{k} h_{T}}{\Omega_{i s}} .
$$

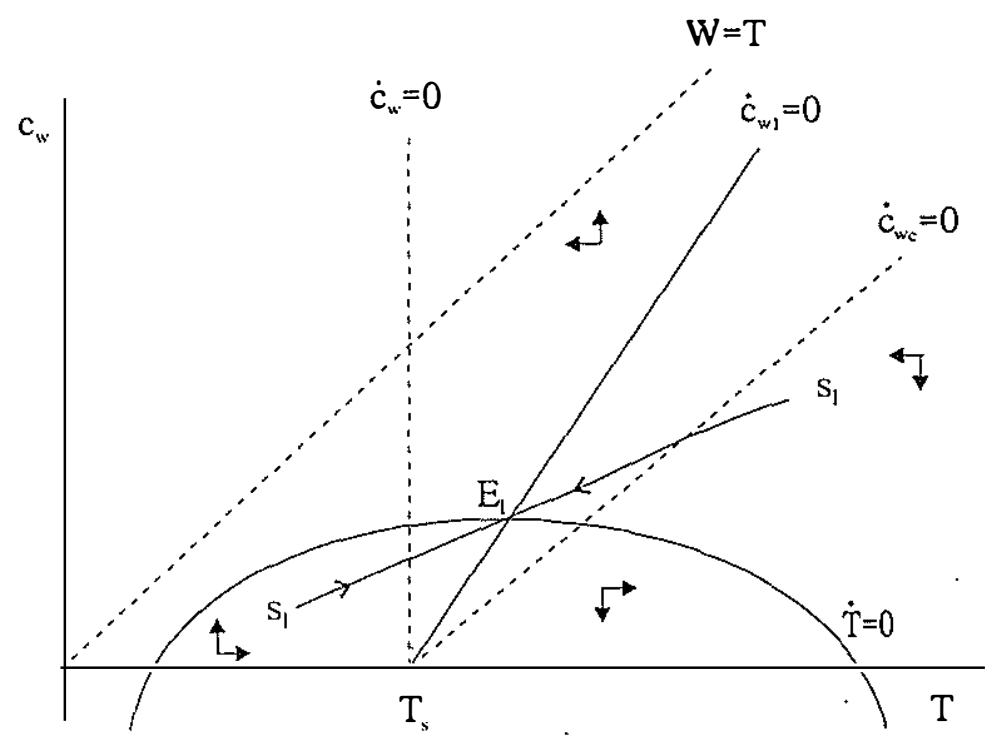

Figure 6.

Figure 6 illustrates the dynamics of the problem. It is very similar to figure 4, but instead of having the amount of wood produced on

13 The derivation of the following equation is analogous to the derivation of equation (16), presented in appendix B. 
the vertical axis, we have the amount of wood consumed by a representative Southern consumer. The schedule $W=T$, below which all points are feasible, has an inclination of $1 / \mathrm{m}^{s}$, instead of 1 as before. The locus $\dot{c}_{W}^{i s}=0$ is represented by the line $\dot{c}_{W 1}=0$ and it is derived from equation (21). The locus $\dot{T}=0$ from the problem's constraints is rewritten as:

$$
c_{W}^{i s}=\frac{G(T)-m^{n} c_{W}^{i n}}{m^{s}}
$$

where $c_{W}^{i n}$ is the consumption of wood from a representative Northern consumer. Observe that when the consumption of wood from Northerners increases, the $\dot{T}=0$ schedule shifts down as its concavity decreases. Similarly to the dynamics depicted in figure 4, the problem represented in figure 6 has only one saddle path, s1s1, leading to point $E_{l}$.

The Southern planner solution to the problem implies a different allocation compared to the market solution for three reasons: the planner incorporates the effect of the consumption of manufactures on the ozone layer, she takes into account the effect of the production of wood on the size of the rain forest and its effect on the ozone, and she exploits the country's monopoly power in the international goods' market.

The implementation of the Southern plamner allocation is achieved in a market enviromment by govermment transfers to consumers to ensure that $\Omega_{i}=1 / \alpha_{i}$, prices normalized so that the multiplier of the balance of payments constraint equals one, and the introduction of: a transfer to each forest owner equal to $\frac{C_{W}^{s}}{C_{W}^{s}+C_{W}^{n}}\left[C_{W}^{s} \frac{\sum_{k=1}^{m^{s}} \Omega_{k} U_{i}^{k} h_{T}}{m^{s} \Omega_{i}}\right]-$ $\frac{C_{W}^{n}}{C_{W}^{s}+C_{W}^{n}}\left[G^{\prime}(T)-\rho\right]$ per tree owned ${ }^{14}$; a consumption tax on manufactures equal to $\sum_{k=1}^{m^{*}} \Omega_{k} U_{z}^{k} h_{M}$; an export tax on wood equal to $\sum_{k=M, W, B}\left[m_{k} \frac{\partial p_{k}\left(m_{M}, m_{W}, m_{B}\right)}{\partial m_{W}}\right]$; an import subsidy on baskets equal to $\sum_{k=M, W, B}\left[m_{k} \frac{\partial p_{k}\left(m_{M}, m_{W}, m_{B}\right)}{\partial m_{B}}\right]$; and an import subsidy on manu-

\footnotetext{
${ }^{11}$ The value of the transfer is derived by writing cquation (21) in terms of $\mathrm{W}$, using $W=m^{n} c_{W}^{i n}+m^{s} c_{1 y}^{i s}$, so that wc can compare it to cquation (11). Hcre, again, each produccr of wood takes the transfer as an cxogenous valuc.
} 
factures equal to $\sum_{k=M, W, B}\left[m_{k} \frac{\partial p_{k}\left(m_{\Lambda s} m_{W}, m_{B}\right)}{\partial m_{M S}}\right]$ in absolute value. Similarly to the Northern plamner case, here the three latter taxes deal with the exploitation of the monopoly power of the country in the international market. The tax on manufactures production is constant over time, and the other taxes change due to changes in the consumption/production of wood along the saddle path.

\section{Comparing the Different Allocations.}

Now the non-cooperative solution will be compared to the cooperative one. First, lets look at the treatment of the manufactures consumption externality. Each national planner does not care about the externality of the consumption of manufactures on the utility of the consumers of the other country. That is the reason for the tax on manufactures (production tax equal to $\sum_{k=1}^{n_{2} n} \Omega_{k} U_{z}^{k} h_{M}$, for North, and consumption tax equal to $\sum_{k=1}^{m_{2}^{s}} \Omega_{k} U_{z}^{k} h_{M}$, for South) to be lower than the tax related to the global planner's optimal allocation (production tax equal to $\sum_{k=1}^{m m^{y}+m{ }^{n}} \Omega_{k} U_{z}^{k} h_{M}$ ). If this were the only difference between the non-cooperative and cooperative solution, then the latter would prescribe a lower consumption level of manufactures, and a larger ozone "consumption". The non-cooperative solution would yield a higher utility level for the consumers compared to laissez-faire, but inferior to the cooperative allocation.

The treatment of the wood production externality requires a more careful analysis. The Northern plamer does not address the problem as it should, incorporating the effect of Northerners consumption of wood on the size of the forest. The Southern planner does deal with the problem, but, here again, she does not care about the Northerners utility, so that she will prescribe a lower transfer to forest owners than the central planner's prescription. In figure 6, the locus $c_{W}=0$ and $c_{W c}=0$ represent the market equilibrium and the central planner schedules, respectively ${ }^{15}$. For a given consumption level of wood by foreign consumers, the optimal path for Southerners consumption in the local planner solution is lower than

${ }^{15}$ The cquation for the $\dot{c}_{1 /} c=0$ schedulc comes from cquation (16), and for the $\dot{c}_{W}=0$ schedule from cquation (13), using that $W=m^{n} c_{W}^{i n}+m^{\dot{s}} c_{W}^{i s}$. 
the market equilibrium and higher than the central plamner solution at each point in time, if they start at the same forest size. It means that when both countries are acting cooperatively and implementing the central planner solution, the Southern govermment will have an incentive to deviate from it, increase their consumption of wood an improve their welfare. If the Northerners respond to that by changing their consumption of wood as well, the $\dot{T}=0$ schedule will shift, and it may be the case that the result will be a lower consumption of wood for Southerners. The size of the forest in the local planner's steady state in unambiguously in between that of the market and central planner solutions.

Finally, the local planners prescribe export taxes and import tariffs to exploit their monopoly power in the world market for goods. These taxes, if taken individually, yield higher welfare for the country that imposes them. However, if the other countries do the same, they result in a lower welfare for everyone. Hence, the improvement in welfare achieved by the policies addressing the other externalities may be suppressed by the "tariff war", resulting in a lower welfare compared to the free market equilibrium.

\section{Concluding Remarks.}

This paper characterizes a situation very similar to the northsouth dilemma we witness in the world. The southern countries of the world, mostly underdeveloped, are the depositories of what remains from the world's natural forests, and they visually use that resource in a destructive way. The preservation of the forests is seen as essential to the rlanet. The northern, developed, countries, on the other hand, are responsible for much of the air pollution in the world. these two phenomena are linked through their effect on the ozone layer. What sort of policy intervention should be used in a situation where there is an environmentally harmful externality of consumption/production that cross countries' frontiers?

A simple model that incorporates the main features needed to characterize the situation described above is constructed. First, the free market equilibrium for the model is identified, and next the world cooperative solution for the problem is derived. With a prescription 
of a set of taxes, we indicated how the global plamner's efficient allocation could be reached in a market situation. The same procedure is taken for national plamners, identifying a situation where countries acts individually in pursuing an allocation that yields higher social welfare.

The best alternative to deal with the sort of externality presented in this paper is when both countries act cooperatively to implement a global planner allocation. The local planners' allocation deals with the environmentally harmful externality problem in a less efficient way compared to the central plamner, but yet it is better than the market allocation with respect to that. However, when both countries implement the local planner solution they may be worse off than in the market solution because of their imposition of import tariffs and export taxes that try to exploit their monopoly power in the international goods' market.

A further development of this analysis should explore whether the cooperative solution is a Nash equilibrium. If the two countries try to implement the global planner allocation, will each country have an incentive to deviate and pursue the national planner allocation? If so, how could the global plamner solution be enforced?

\section{Appendix A}

This appendix checks why other trajectories do not satisfy the first order conditions for the maximization problem in section 2 . First, suppose that the initial size of the forest is $T^{\prime}, T^{\prime}>T_{s}$. Consider a trajectory starting at $W=s^{\prime}, s^{\prime}>s$. This trajectory will eventually reach the $W=T$ line (point $F^{\prime}$ in Figure 4). At that point conditions (12.iv) and (13) become inconsistent. Hence it cannot be an optimal path.

Now consider a trajectory starting at $s^{\prime \prime}, s^{\prime \prime}<s$. This trajectory goes to point $F^{\prime \prime}$ in the figure. But at $F^{\prime \prime}$ the amount of wood produced is equal to zero, and the optimal adjustment path for the production of wood (equation(13)) becomes indeterminate. It cannot be an optimal path either. 


\section{Appendix B}

From the first order conditions for the dynamic maximization problem in equation (15) we have:

$$
-\frac{\partial H}{\partial T}=\frac{\partial\left[y e^{-\rho(\tau-t)}\right]}{\partial \tau}
$$

where $H$ is the Hamiltonian equation associated to the problem, and $y e^{-\rho(\tau-t)}$ is the costate variable.

Equation (B1) can be rewritten as:

$$
\dot{y}=\left[\rho-G^{\prime}(T)\right] y-\sum_{k=i}^{m_{2}} \Omega_{k} U_{z}^{k} h_{T}
$$

When maximizing with respect to $W$ and $c_{W}^{i}$ we get, respectively:

$$
\begin{aligned}
& \text { (i) } \pi_{W}-y=0 \\
& \text { (ii) } \Omega_{i} U_{c_{W}}^{i}-\pi_{W}=0
\end{aligned}
$$

where $\pi_{W}$ is the Lagrange multiplier associated to the wood market clearing condition.

Combining equations (B2) and (B3) we get:

$$
\Omega_{i} U_{c W w^{\prime}}^{i} \dot{c}_{W}^{i}=\left[\rho-G^{\prime}(T)\right] \Omega_{i} U_{c_{w^{\prime}}}^{i}-\sum_{k=1}^{m} \Omega_{k} U_{z}^{k} h_{T} .
$$

Assuming that all consumers are equally treated in the welfare function, i.e., $\Omega_{i}$ is the same for any $i$. Using equation (2) to derive $U_{c_{W}}^{i}$ and $U_{\mathcal{c}^{\prime} \mathcal{C}_{W}}^{i}$, and substituting in (B4) equation (16) is derived. Remembering that in equilibrium all consumers will consume the same amount of each good $\left(m c_{W}^{i}=W\right)$, then equation (16) can be rewritten as equation (17). 


\section{References}

Bhagwati, J.N. 1981. "The Generalized theory of distortions and welfare." In Bhagwati, J.N. (ed.), International Trade: Selected Readings. Cambridge: The MIT Press.

Blanchard, O. \& S. Fisher 1989. Lectures on Macroeconomics. Cambridge: MIT Press.

Dasgupta, P.S. \& G.M. Heal 1979. Economic Theory and Exhaustible Resources. Cambridge Economic Handbooks, University Press..

Dixit, A. 1985. "Tax policy in open economies." In Auerbach A.J. \& M. Feldstein (eds.), Handbook of Public Economics. North-Holland: Elsevier Science Publishers B.V..

Intriligator, M. 1971. Mathematical Optimization and Economic Theory. Prentice Hall: Englewood Cliffs.

Johnson, H.G. 1981. "Optimal trade intervention in the presence of domestic distortions." In Bhagwati, J.N. (ed.), International Trade: Selected Readings. Cambridge: The MIT Press.

Markusen, J. 1975. "International externalities and optimal tax structures." Journal of International Economics 5: 15-29. 